\title{
La erosión de la endogamia o de la dinámica del mestizaje. Aguascalientes, Nueva Galicia, siglos XVII y XVIII
}

\section{The Erosion of Endogamy, or the Dynamics of Miscegenation. Aguascalientes, Nueva Galicia, $17^{\text {th }}$ and $18^{\text {th }}$ centuries}

Víctor M. González Esparza

Departamento de Historia, Universidad Autónoma de Aguascalientes

vgonzalez@correo.uaa.mx

DOI: I0.2490I/rehs.v40i157.322

\section{(c) 7 (i) (8)}

La erosión de la endogamia o de la dinámica del mestizaje. Aguascalientes, Nueva Galicia, siglos XVII y XVIII por Víctor M. González Esparza se distribuye bajo una Licencia Creative Commons Atribución-NoComercial 4.0 Internacional.

Fecha de recepción: 30 de junio de 2017

Fecha de aprobación: I 8 de mayo de 2018

\section{RESUMEN:}

El ensayo tiene como propósito participar en un debate no resuelto sobre el grado de flexibilidad de la sociedad novohispana, con base en el análisis de los matrimonios mixtos durante los siglos XVII y XVIII, en una tendencia que muestra la erosión de la endogamia así como la relevancia de las castas en la conformación social de Aguascalientes, en la Nueva Galicia. La información es aprovechada para una reflexión amplia sobre el mestizaje en Tierra Adentro, una región poco analizada dentro de la historiografía sobre africanos y sus descendientes. Las fuentes comprenden 200 años de registros parroquiales, lo que ofrece una lectura serial y sistemática sobre las interrelaciones entre las diferentes "calidades".

Palabras clave:

Matrimonios mixtos, mestizaje, Tierra Adentro, Nueva Galicia, Aguascalientes.

\section{ABSTRACT:}

The objective of the essay is to contribute to the still-unresolved debate on the degree of flexibility that existed in the society of New Spain. The study is based on the analysis of mixed 
marriages in the $\mathrm{I} 7^{\text {th }}$ and $\mathrm{I} 8^{\text {th }}$ centuries, which revealed a trend towards the erosion of endogamy, as well as the importance that caste affiliation maintained in the social conformation of Aguascalientes, Nueva Galicia. But the data gathered also provide the basis for a broader reflection on miscegenation in Tierra Adentro, a little-studied region in the historiography of Africans and their descendants. The documental sources used include 200 years of parish records that offer a serial and systematic reading of the interrelations among the different castes (calidades).

Keywords:

Mixed marriages, mestizaje, Tierra Adentro, Nueva Galicia, Aguascalientes

"A final de cuentas, siempre se trata de aumentar el número de jugadores, o sea, de volver a la complejidad y a la diversidad de la situación inicial"

Claude Lévi-Strauss, "Raza e Historia", Raza y cultura.

"las mezclas y los mestizajes pierden el aspecto de un desorden pasajero para convertirse en una dinámica fundamental"

Serge Gruzinski, El pensamiento mestizo.

Introducción

La crítica al "mito" del mestizaje en México por sus connotaciones raciales y por antiliberal realizada hace algunos años por prestigiados historiadores, ${ }^{\perp}$ quedó como una asignatura pendiente para la realización de estudios más concretos en términos históricos. Este artículo retoma la propuesta de profundizar en el tema, a partir de la dinámica que se puede observar a través de los matrimonios entre las diferentes castas y calidades. ${ }^{2}$ En este sentido, el objetivo de este trabajo es mostrar la importancia del mestizaje en Tierra Adentro, particularmente a través del análisis de los matrimonios mixtos y del papel de los afrodescendientes en la mezcla social, con base en el estudio de caso sobre Aguascalientes en los siglos XVII y XVIII.

Ciertamente el concepto del mestizaje a partir de la fusión entre españoles e indígenas, como producto del patriotismo criollo, que se desarrolla en el siglo XIX (por cierto con liberales mexicanos) y que se renueva con la "raza cósmica" vasconcelista, ${ }^{3}$ no corresponde a la diversidad del presente ni tampoco, como lo ha mostrado una amplia historiografía, a los estudios históricos más detallados.

La crítica más importante a la estrecha idea del mestizaje decimonónico ha sido realizada por la historiografía sobre africanos y afrodescendientes en la Nueva España. El viejo proyecto de Aguirre Beltrán de reconocer las aportaciones de los afrodescendientes a la sociedad y la cultura mexicana, sin duda ha logrado su objetivo. Se puede afirmar en este sentido que la historiografía más fructífera para México y en general para América Latina en la última generación de 
historiadores se ha desarrollado sobre la presencia africana en estos territorios, particularmente durante la época colonial.4

Ahora bien, la relevancia de las raíces afromestizas no ha estado conectada con el proceso mismo del mestizaje y la flexibilidad de la sociedad de castas. ${ }^{5}$ La flexibilidad es característica del sistema, dada la concepción "pactista" entre el rey y sus súbditos; sin embargo, es también una construcción social a partir de prácticas no promovidas por la propia Corona e incluso, por momentos, prácticas no permitidas y por ello transgresoras. De ahí la importancia de profundizar en el tema a partir, por ejemplo, de un indicador sensible como lo es el de matrimonios mixtos. $\underline{6}$

En este sentido, el concepto de mestizaje, más allá de sus usos ideológicos en el pasado, es una herramienta para combatir los esencialismos, sean producto del nacionalismo o de la antropología más politizada, ${ }^{7}$ por lo que no podemos desecharlo sin antes conocer las dinámicas de las interrelaciones sociales en el periodo novohispano.

El presente trabajo se inscribe en una reflexión más amplia sobre el mestizaje, por lo que en primer lugar realizo una revisión historiográfica, particularmente sobre los matrimonios mixtos, uno de los indicadores clave que puede ayudarnos a comprender la flexibilidad de la sociedad novohispana. Posteriormente paso al análisis específico del caso de Aguascalientes durante los siglos XVII y XVIII, con el fin de mostrar la erosión de la endogamia en las diferentes calidades, enfatizando el papel de "catalizador" que llevaron a cabo las castas. Finalmente realizo una propuesta de análisis comparativo sobre los porcentajes de heterogamia en la Nueva España (los matrimonios fuera de la misma calidad), con el fin de avanzar en el conocimiento de las diferencias regionales y en la necesaria resignificación sobre el mestizaje.

Las fuentes utilizadas son los registros parroquiales de Aguascalientes, que afortunadamente guardan una relevante continuidad, especialmente en el registro de las calidades. Este estudio ha sido posible, entre otras cosas, gracias a la plataforma realizada por el proyecto de Family Search, la cual más allá de sus propósitos originales ahora nos permite consultar las actas de manera digitalizada. El trabajo concluye por el momento en i8oo, sin embargo, aspiro a que en un futuro próximo pueda ampliarlo hasta la desaparición de las castas y calidades en los registros del siglo XIX.

La historiografía sobre el mestizaje y los matrimonios mixtos

Como lo hemos comentado, el uso del concepto de mestizaje en términos ideológicos es una creación del nacionalismo criollo y fue reforzado a partir de la Revolución en el siglo XX. Los estudios pioneros sobre el mestizaje en Hispanoamérica fueron los de Richard Konetzke y Magnus Mörner en momentos en que predominaban las ideologías racistas. Quizá por ello pudieron apreciar la diferencia de este proceso en la primera América y especialmente en el septentrión novohispano. 
Para Konetzke la legislación indiana no favoreció el matrimonio mixto y se dedicó bastante a difundir la "política de separación" entre las calidades, además de que comentó algo central para entender el mestizaje: que dicha "política de separación" de las calidades no tenía objetivos raciales, en estricto sentido, sino fundamentalmente religiosos y de seguridad, es decir, evangelizar y proteger sobre todo a los indios. Más aún, fue el clero quien favoreció los matrimonios mixtos a partir de la libre elección de la pareja, por medio de matrimonios legales, siempre y cuando los indios estuvieran evangelizados. $\underline{\underline{8}}$

Para Mörner, la importancia del mestizaje estribaba en su respuesta al medio, como una "resistencia india contra otras enfermedades", por lo que el objetivo de mostrar la importancia del mestizaje, precisamente en los años de la posguerra, era señalar "la grandeza humana y social del mestizaje". ${ }^{2}$ Mörner realizó excelentes discusiones historiográficas sobre sus temas, y dejó ver la necesidad de estudios más detallados, con base en las fuentes demográficas y que incluyeran las diferencias regionales, no obstante que sería uno de los autores en acentuar las permanencias de la "sociedad de castas". Ambos autores, Konetzke y Mörner, sentaron las bases incluso para una polémica que permanece hasta la actualidad sobre el carácter flexible o cerrado de la sociedad novohispana.

Uno de los primeros estudios que utilizó los matrimonios mixtos como indicador de las características de la sociedad novohispana lo realizó Marcelo Carmagnani, quien además de señalar el crecimiento de los bautizos particularmente a partir de los setenta del siglo XVII en Charcas, San Luis Potosí, encontró formas endogámicas a partir de la conservación de una identidad étnica en el caso de los indígenas, frente a la "dispersión" de otros grupos como los "negros" y mulatos. - Este trabajo de Carmagnani mantenía la idea de la mayor endogamia de los indígenas a partir de la cultura, y de alguna manera el predominio del concepto de raza entre españoles y castas (en una suerte de dicotomía entre cultura y raza), si bien fue el primero en registrar la dinámica endogámica y exogámica entre las diferentes calidades.

Investigaciones posteriores reforzaron las características endogámicas tanto de españoles como de indígenas, en el sentido de que la "calidad" era lo más determinante en la elección de pareja. El trabajo de historiadoras pioneras en el tema de la familia habla de esta tendencia. Por ejemplo, Cecilia Rabell estudió el caso de San Luis de la Paz, en el estado de Guanajuato, y comentó sobre estas tendencias endogámicas de indígenas (90 \% se casaban entre sí) y de españoles (65\% en promedio), si bien las castas eran claramente exogámicas (sólo 40 \% en promedio se casaban entre sí).!I

De hecho, Rabell apuntó en las conclusiones un tema que me parece fundamental: "Los mestizos no desdeñan el matrimonio con las castas ni, por supuesto, con los españoles. Son el grupo 'puente' que une a todas las calidades de la población no india". ㄹ. Se refiere sólo al caso de mestizos, sin embargo, puede observarse en general para las castas, aunque desafortunadamente no profundizó en el tema.

Otros autores retomaron el estudio de esta dinámica a partir de considerar a los grupos de afrodescendientes como un "puente" entre las diferentes cualidades étnicas o bien como un pilar 
en el mestizaje. "I3 “La información disponible, comentó Patrick J. Carroll, indica que los 'negros' africanos, casi olvidados, y sus descendientes aportaron una de las más grandes -si no proporcionalmente la mayor contribución al mestizaje". ${ }^{ \pm 4}$ El ejemplo que utiliza el autor es Veracruz, particularmente Xalapa y Córdoba, en comparación con otros estudios en Cholula (Puebla), $\stackrel{15}{y}$ concluye que los archivos parroquiales muestran que los "americanos negros y sus descendientes criollos de casta, asumieron posiciones intermedias entre las comunidades locales de hispanos blancos y los indios [...] Juntos, los americanos negros y los mestizos atrajeron a los indios y a los blancos a este ambiente social intermedio, dominado por las castas". $\underline{\underline{6}}$

Rabell enfatizó el papel de los mestizos como "puente" para unir las diferentes calidades, y Carroll lo hizo en el mismo sentido pero con énfasis en los afrodescendientes, la primera lo refirió a Guanajuato y el segundo a Veracruz quizá por ello las diferencias. Además, el propósito de sus estudios era diferente, en un caso mostrar que la "calidad" predominaba sobre la clase en la elección de pareja, en otro, mostrar la relevancia de las aportaciones de los afrodescendientes.

Ya en el siglo XXI, la demografía histórica sobre Nueva España se ha renovado. El estudio de Castillo Palma mostró con claridad las estrategias utilizadas para cruzar la barrera de color, como la de no pagar impuestos o disminuirlos, pero sobre todo de cómo las castas se multiplicaron aceleradamente en el siglo XVII de tal manera que los matrimonios mixtos tendieron a incrementarse. ${ }^{17}$ Los estudios de Chantal Cramaussel, David Carbajal, José Gustavo González Flores, entre otros, nos han advertido sobre la existencia de "familias pluriétnicas" (con diferentes registros de calidad entre los miembros de una misma familia), estudios que muestran una sociedad plural, flexible y con altos porcentajes de heterogamia en el matrimonio propiciados particularmente por las castas. $\frac{18}{-}$

Otro de los debates centrales que dejó ver tempranamente las diferentes posturas sobre la sociedad novohispana y que tuvo como eje central la endogamia o exogamia de los matrimonios, fue generado por el artículo de William B. Taylor y John K. Chance sobre estamentos y clases en Oaxaca colonial. I9 Su conclusión fue que Antequera a fines de la época colonial, con un fuerte crecimiento económico a partir de las reformas Borbónicas, observó la reducción de la efectividad del sistema de castas como uno de los principales determinantes de la estratificación, por lo que el estatus sociorracial fue cada vez más dependiente de consideraciones económicas..$^{20}$

La crítica a este ensayo de Taylor y Chance, que además generó toda una serie de respuestas y contrarrespuestas con aportaciones cada vez más sofisticadas en términos estadísticos, fue realizada conjuntamente por Robert McCaa, Stuart B. Schwartz y Arturo Grubessich, debido a lo que consideraron errores conceptuales y metodológicos. . $^{-}$Sus argumentos son dignos de recordar: los cambios en la terminología sociorracial de una fuente a otra e incluso para un mismo individuo; la necesidad de declarar para los censos o padrones el estatus de acuerdo a la normatividad, sobre todo después de la Pragmática de i776; el uso de porcentajes en lugar de indicadores compuestos, ya que esta diferencia metodológica puede variar los resultados además de que permite la comparación. A partir de ello, proponen un índice para analizar la endogamia en los matrimonios y, a diferencia de Taylor y Chance, encontraron que la endogamia era muy 
fuerte para todos los grupos, por lo que los criterios sociorraciales para McCaa y compañía fueron el principal determinante de la estratificación en Oaxaca colonial. ${ }^{22}$

Como bien lo comentó Patricia Seed, la principal discusión, más allá de las ocupaciones y la estratificación, tenía que ver con la endogamia y su relación con las características de la sociedad novohispana, como sociedad de castas (cerrada) o como sociedad de clases (abierta). ${ }^{23}$ Así pues, lo que dejó esta polémica es que el análisis de los matrimonios interraciales era un indicador sensible, incluso para determinar los grados de flexibilidad de la sociedad novohispana: a mayor grado de heterogamia, mayor mestizaje y flexibilidad de la sociedad. Por ello la necesidad de construir indicadores no por ser sofisticados sino por su pertinencia para medir los grados y matices, así como las diferencias regionales, de esta flexibilidad.

\section{La población plural de Aguascalientes}

En este apartado analizaré la demografía de la parroquia de Aguascalientes en los siglos XVII y XVIII, con el fin de contextualizar el poblamiento y la pluralidad social que dio origen a esta villa. Fundada en ${ }^{5} 575$, la villa de la Asunción se estableció en el espacio de un fuerte, un "sitio y paso", un "puesto de carretas" llamado de las Aguas calientes, en tierras que pertenecieron a la Provincia de Ávalos. ${ }^{24}$ Su origen se explica por razones de seguridad en el momento de la guerra contra los indios, pero debería su crecimiento a su ubicación para el abastecimiento de las minas de Zacatecas. Los primeros testimonios, como el de Hernando Gallegos de 1584, hablan de las dificultades para mantener la villa bajo una política de colonización "a fuego y sangre" contra los indios llamados chichimecas; ${ }^{25}$ de acuerdo con el de Mota y Escobar (ca. I605), era la villa más pobre de todo el reino de Nueva Galicia. ${ }^{26}$ Sin embargo, el testimonio de Domingo Lázaro de Arregui (I62I) nos informa que Aguascalientes ya se había separado de la Alcaldía de Lagos conformando una propia, y de algo más importante: que el Camino Real, que venía de la Ciudad de México para Zacatecas, pasaba ya por la villa de Aguascalientes: "El camino real dejamos en el pueblo de Mitic desde donde el rumbo que llevamos se endereza más al norte dejando Los Lagos a la mano derecha y Teocaltiche a la izquierda, y pasa el camino por Aguas Calientes"..27

El cambio de política imperial a favor del poblamiento junto con el paso del Camino Real por la villa, $\underline{\underline{28}}$ favoreció la cercanía con las minas zacatecanas y el crecimiento de la nueva Alcaldía de Aguascalientes. De ahí la relevancia que la visita de Gaspar de la Fuente (I608-I609)ำtuviera en la región a fin de construir el corazón de la villa, la plaza de armas, y con ello dar posibilidades de poblamiento, repartiendo solares y distribuyendo el agua de las huertas. Y al mismo tiempo, con el crecimiento de la población de los ganados, hacer posible la reorganización espacial a través de la formación de las grandes haciendas, procesos todos que permitirían el crecimiento de la villa y la región en el siglo XVII, el llamado siglo de la crisis.

El estudio de la historia demográfica en el siglo XVII muestra una gran diversidad, principalmente entre el norte y sur de la Nueva España. Los primeros trabajos sobre el centro sur de la Nueva España mostraron que la población se estancó e incluso decreció dadas las emigraciones. ${ }^{30}$ Por el contrario, en un pueblo minero del norte de la Nueva España, Marcelo Carmagnani, además de encontrar formas complejas del hibridaje como lo comentamos, señaló 
el crecimiento de los bautizos particularmente a partir de los años setenta del siglo XVII en Charcas, San Luis Potosí.

En el mismo sentido, los estudios para el septentrión novohispano muestran un proceso acelerado de poblamiento, particularmente a partir de la segunda mitad del siglo XVII, quizá desde la fundación de Parral en r63r..$^{32}$ El crecimiento de Aguascalientes habría que ubicarlo en este contexto de expansión y colonización hacia el norte novohispano, correlacionado con la recuperación de la minería en general de la Nueva Galicia (de Durango y Sombrerete por ejemplo), además de la propia Zacatecas. ${ }^{33}$

Gráfica I. Crecimiento Vegetativo por calidades, Aguascalientes siglo XVII

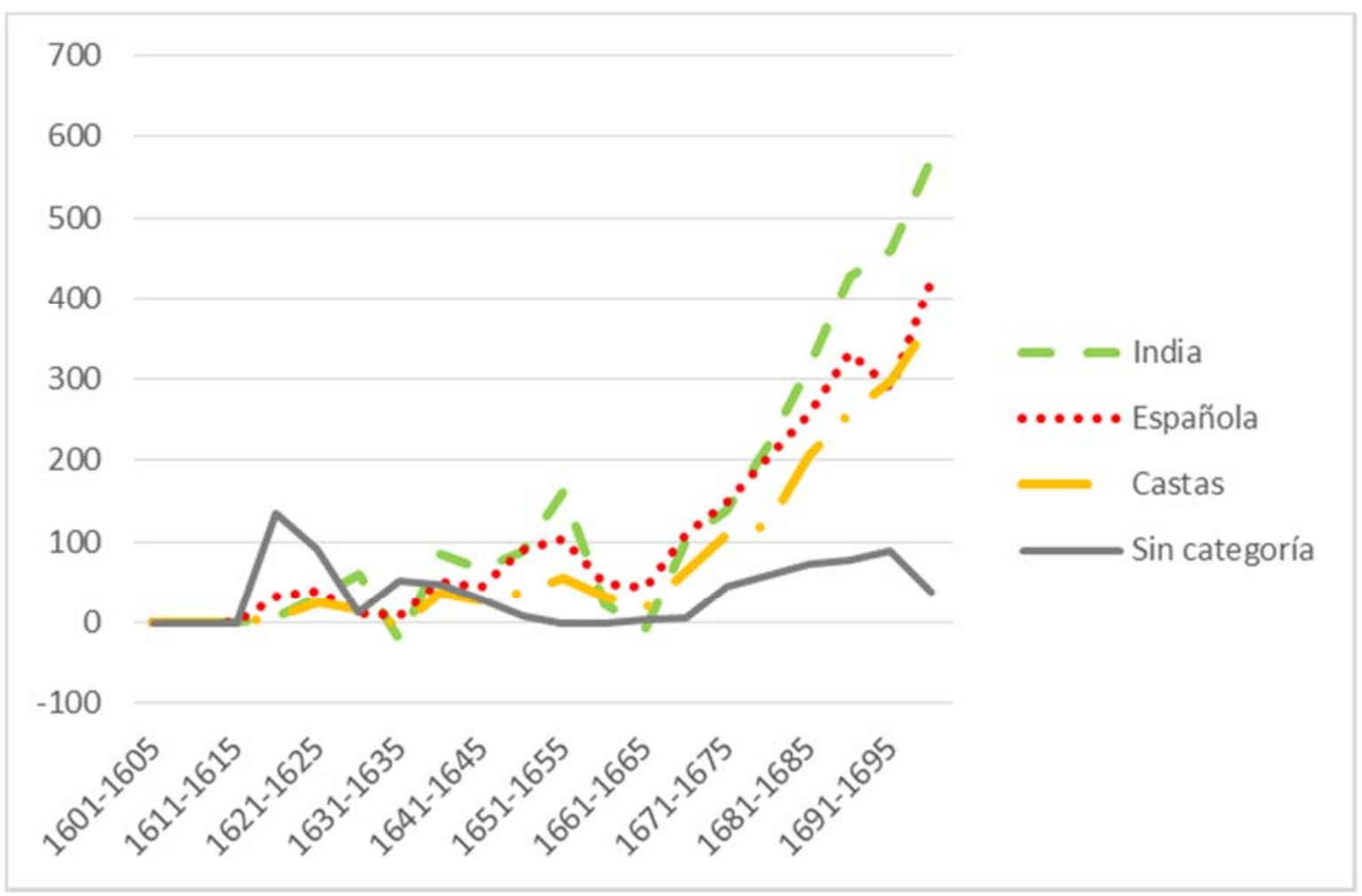

Fuente: Elaboración propia, con información de Family Search, "Archivos Parroquiales de Aguascalientes, Bautizos y Defunciones, siglo XVII".

El otro aspecto por considerar en este momento de expansión es la recuperación de la población india en Tierra Adentro, de la incorporación de la población española pero también, de un alto porcentaje de crecimiento de las castas, es decir, de mestizos, mulatos y afrodescendientes en general. El crecimiento vegetativo (bautizos menos entierros) por calidades muestra esta tendencia plural en la composición de la población de Aguascalientes, con especial participación porcentual de las castas en una zona poco estudiada en este sentido, la cual se observa por ejemplo desde el primer Padrón de I648 en donde el porcentaje de la población era de 37 \% para indios, $35.6 \%$ para castas y un $27 \%$ para españoles. ${ }^{34}$ 
Para el siglo XVIII destaca el crecimiento sostenido de la población, a un ritmo del $4 \%$ anual, uno de los más altos en comparación a la tendencia ambivalente de la población del centro sur de la Nueva España. Dentro de esta expansión hay otro dato significativo que es necesario estudiar con más profundidad: el incremento exponencial en los registros de la población india, frente a los de españoles y castas. ${ }^{35}$

Gráfica 2. Crecimiento vegetativo por calidad, Aguascalientes siglo XVIII

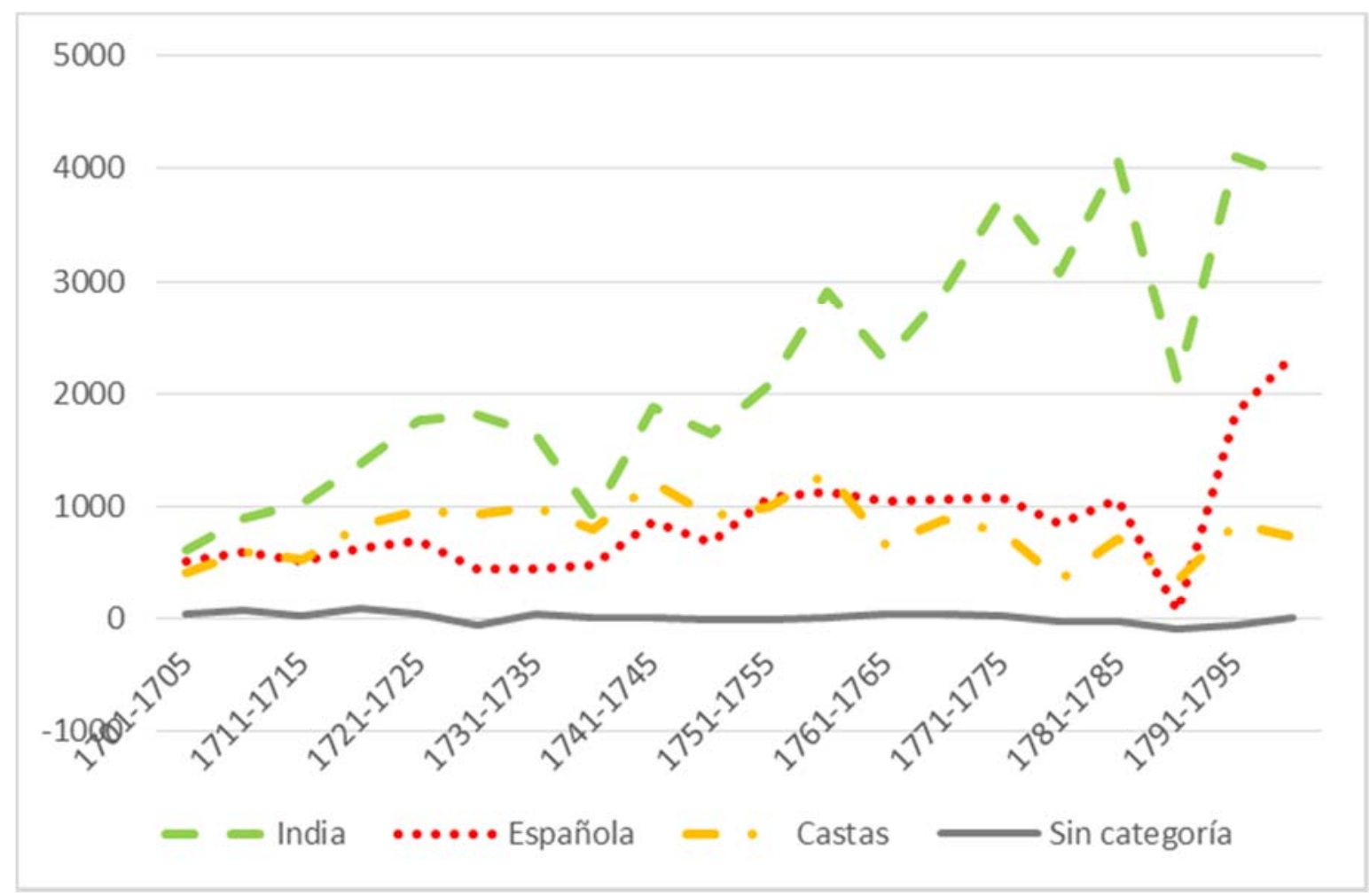

Fuente: Elaboración propia, con información de Family Search, "Archivos Parroquiales de Aguascalientes, Bautizos y Defunciones, siglo XVIII".

Como ya se ha comentado en varios estudios, los datos obtenidos de los registros parroquiales y los de los Padrones y Censos no se corresponden entre sí, quizá porque los Censos y Padrones trataban de mantener las clasificaciones a nivel normativo. Para el caso de Aguascalientes, de acuerdo a los registros parroquiales, el mayor número de registros corresponde a la población india (con un $56 \%$ a partir del crecimiento vegetativo), con una gran diferencia con respecto a los otros grupos: españoles (23 \%) y castas (20\%); sin embargo, si observamos la información del Censo General de la Intendencia integrado por Menéndez Valdés en I79I-I793, la proporción cambia para la Subdelegación de Aguascalientes: 39 \% de españoles y europeos; $33.5 \%$ de indios y $27.5 \%$ de castas. ${ }^{36}$

Más allá de los registros, habría que explicar estas contradicciones a partir de contextos que es necesario explorar. Por ejemplo, Mörner de hecho lo sugiere, ante las grandes crisis de mortalidad la población india encontró en la mezcla una forma de resistencia incluso biológica 
ante las epidemias. ${ }^{37}$ Otro tema por explorar a partir del incremento de los registros de población india es el de la presión fiscal, es decir, la necesidad de ampliar la base de tributarios por parte de la Corona, pero también como estrategia de la población de castas (sobre todo mulatos y negros) de pagar menos impuestos. Y finalmente, se requiere explorar la estrategia de las castas de mezclarse con indios para tener acceso a la tierra, temas que merecen un estudio en particular.

Ciertamente existe el riesgo de no encontrar las relaciones entre registros y prácticas. No obstante, es necesario profundizar con más detalle e incluso sugerir algunos indicadores que permitan la comparación, con el fin de conocer las diferentes dinámicas del mestizaje en la Nueva España, por lo que es necesario adentrarnos en las fuentes particularmente de los matrimonios mixtos.

Los matrimonios mixtos o de la erosión de la endogamia

Toda historia incluida la serial es un artificio, sin embargo, la larga duración nos permite buscar "el espesor de lo cultural y de lo social". ${ }^{8}$ Es decir, los registros parroquiales son representaciones sobre la clasificación social propia de la época, tanto de los párrocos como también de cómo se representaban a sí mismos los propios pobladores, por lo que más allá de los casos individuales hay regularidades, como veremos, que nos permiten acercarnos a dinámicas más amplias. En este sentido, el hallazgo que ha representado la reconstitución de familias pluriétnicas ha tenido como implicación el cuestionamiento a los registros, dada la variabilidad de las calidades para una misma persona; incluso un autor de esta nueva demografía histórica para la Nueva España ha denominado el proceso como "mestizaje de papel", para representar que el registro de las calidades no correspondía efectivamente a los diferentes grupos de la sociedad novohispana y, más aún, que las mezclas sociales eran sólo una representación en donde los sacerdotes como mediadores jugaban un papel central.39

Si se observa un caso de manera individual, efectivamente, los registros de una persona con diferentes calidades pueden parecer arbitrarios. Sin embargo, habría que recordar que precisamente una de las características de la historia serial (de largo plazo), aceptando que todo registro es una representación o un artificio, es observar los registros en conjunto como representaciones sociales, de tal manera que se puedan encontrar algunas regularidades (ese "espesor social" del que hablara Chaunu) más allá de los criterios de un sacerdote o del propio individuo que buscaba su registro bajo diferentes calidades, probablemente como una estrategia de sobrevivencia o incluso de movilidad social. ${ }^{40}$ Esas regularidades son las que pretendo mostrar con el análisis siguiente de los matrimonios mixtos.

El análisis de los registros matrimoniales para Aguascalientes comprende de I6o2 a I8oo. Utilizo el indicador sugerido por Robert McCaa, a partir de David Strauss, porque ofrece mayores posibilidades en comparaciones más precisas. ${ }^{4 I}$ Por otra parte, sólo utilizo tres calidades, es decir españoles, indígenas y castas, dado que el comportamiento de mestizos y mulatos es muy similar, lo que hace pensar en que existe una mayor correspondencia entre estos grupos, por lo cual los he integrado en el concepto de castas..$^{22}$ 
Cuadro r. Matrimonios en Aguascalientes, siglo XVII

\begin{tabular}{|l|r|r|r|r|}
\hline & Novias & Novios & Matrimonios endogámicos & \multicolumn{2}{|l|}{ Total de matrimonios } \\
\hline Indios & 737 & 723 & 616 & 723 \\
\hline Españoles & $4 \mathrm{I} 6$ & 430 & $38 \mathrm{I}$ & 430 \\
\hline Castas & 346 & 388 & 243 & 388 \\
\hline Sin calidad & 364 & 322 & 3515 & 322 \\
\hline Total & $\mathrm{I}, 863$ & $\mathrm{I}, 863$ & $\mathrm{I}, 555$ & $\mathrm{I}, 863$ \\
\hline
\end{tabular}

Fuente: Registros parroquiales en Family Search, "Family history library, Aguascalientes, Matrimonios, I602-I700".

Cuadro 2. Índice de Endogamia. Aguascalientes siglo XVII

\begin{tabular}{|c|c|c|c|c|c|}
\hline & Po & $E i$ & $\mathrm{Pe}$ & $P^{*}$ & $K^{*}$ \\
\hline Indios & 0.33 & 286 & 0.15 & 0.39 & 0.76 \\
\hline Españoles & 0.20 & 96 & 0.05 & 0.22 & 0.89 \\
\hline Castas & 0.13 & $7^{2}$ & 0.04 & 0.19 & 0.62 \\
\hline Sin calidad & O.I7 & 63 & 0.03 & O.I7 & 0.97 \\
\hline
\end{tabular}

De acuerdo con este indicador, en el siglo XVII en la parroquia de Aguascalientes, la mayor endogamia se dio entre españoles (o.89) e indios (0.76), lo que viene a corroborar que fueron las castas con 0.62 las que procuraron matrimonios fuera de su propio grupo. ¿Con quiénes tuvieron más matrimonios fuera de su grupo? Principalmente las novias de las castas se casaban con indios (77 casos para el siglo XVII); y los novios de las castas con mujeres indias (Io6 casos).

Si analizamos este mismo tema para el siglo XVIII esta tendencia se amplía, en este caso con más de 20 mil matrimonios considerados:

Cuadro 3. Matrimonios en Aguascalientes, siglo XVIII 


\begin{tabular}{|c|c|c|c|c|}
\hline & Novias & Novios & Matrimonios endogámicos & Total de matrimonios \\
\hline Indios & 7,682 & 8,487 & 6,106 & 8,487 \\
\hline Españoles & 7,586 & 6,923 & 6,119 & 6,923 \\
\hline Castas & 4,967 & 4,827 & 2,734 & 4,827 \\
\hline Sin calidad & 598 & 596 & 596 & 596 \\
\hline Total & 20,833 & 20,833 & 15,555 & 20,833 \\
\hline
\end{tabular}

Fuente: Registros parroquiales en Family Search, "Family history library, Aguascalientes, Matrimonios, I70I-I800".

Cuadro 4. Índice de Endogamia, Aguascalientes, siglo XVIII

\begin{tabular}{|c|c|c|c|c|c|}
\hline & Po & $E i$ & $P e$ & $P *$ & $K^{*}$ \\
\hline Indios & 0.29 & 3,130 & O.I 5 & $0.4 \mathrm{I}$ & 0.56 \\
\hline Españoles & 0.29 & $2,5^{2 \mathrm{I}}$ & O.I2 & 0.36 & $0.7 \mathrm{I}$ \\
\hline Castas & O.I3 & $\mathrm{I}, \mathrm{I} 5 \mathrm{I}$ & 0.06 & 0.24 & $0.4 \mathrm{I}$ \\
\hline Sin calidad & 0.03 & I7 & O.OO & 0.03 & I.OO \\
\hline
\end{tabular}

Para este siglo XVIII, la endogamia seguía siendo mayormente entre los españoles (o.7I), pero para el caso de indios el índice baja 20 puntos (de 0.76 a 0.56), acercándose cada vez más al indicador de las castas (o.4I), lo que demuestra una amplia y gran interrelación entre castas e indios. Concretamente, para el siglo XVIII hubo I,695 matrimonios entre novias de las castas e indios, y I, 3 Iо casos entre novios de las castas e indias.

Este hibridismo propio de una interrelación profunda, también corresponderá aunque en menor escala a matrimonios entre mujeres de las castas y españoles (con 538 matrimonios), prácticamente el doble que entre mujeres indias y españoles (266 casos). Este solo dato nos habla de la proporción que existía en las mezclas entre españoles e indios, lo cual deja sin contenidos históricos prácticamente la idea tradicional del mestizaje. 
Sin embargo, el caso que quizá nos hable de cómo las mezclas y, por lo tanto, la erosión de la endogamia se comportaban, tiene que ver con el matrimonio de mujeres españolas con hombres de las castas (con 78 I matrimonios) para el siglo XVIII; además también vemos matrimonios de estas mujeres españolas con hombres indios (con 686 casos).

Ello nos habla de la erosión de la endogamia, a pesar del reforzamiento de la autoridad de los padres a partir de la Pragmática de $1776-1778$ para impedir el casamiento entre diferentes calidades. Un análisis del índice de endogamia para los últimos 25 años del siglo XVIII, nos advierte que el impacto de esta Pragmática se observa sobre todo entre españoles e indígenas, dado que el índice de endogamia entre estos grupos se incrementa. Entre los españoles, en el último cuarto de dicho siglo el índice sube cuatro puntos en comparación al índice general para todo el siglo, y entre indios sube nueve puntos (a o.65) en este mismo sentido. Mientras que entre las castas, el índice de endogamia baja por el contrario 5 puntos en este mismo periodo comparativo. Ante la pregunta de si la Pragmática de $1776-1778$ frenó los matrimonios mixtos, habría que responder afirmativamente, particularmente entre indios y españoles, no así en el caso de las castas.

En términos generales, si la disminución de la endogamia es un indicador sensible, el caso de la parroquia de Aguascalientes en el siglo XVIII puede ayudarnos a entender los ritmos y el grado en que el mestizaje se realizaba en una sociedad ideológicamente criolla. Porque más allá de reconocer la tendencia endogámica de españoles e indígenas, lo importante es conocer la manera en que se dio la dinámica de la hibridación social. Lo que podemos observar en estos datos sobre Aguascalientes, es que en el largo plazo la endogamia se erosionó principalmente en el siglo XVIII, que las castas jugaron un papel central en esta hibridación social y, gracias a ello, pese a prohibiciones, la sociedad se flexibilizó. Más aún, dentro de las castas, el papel de las mujeres para interaccionar con otros grupos fue más activo por ejemplo en Aguascalientes que paradójicamente en Veracruz. Comparar esta información ayudaría a explicar no sólo las diferencias y el grado de interrelación entre las calidades en las distintas regiones de la Nueva España, y entre ésta y el resto de América Latina, lo cual sigue siendo una tarea pendiente.

Un primer ejercicio de comparación es el siguiente, aunque dado que los registros no son continuos ni tampoco están preparados para utilizar el mismo índice de endogamia utilizado anteriormente, los promedios simples pueden darnos una primera aproximación a un ejercicio de comparación. A diferencia también de los anteriores cuadros sobre endogamia, en este caso observo el porcentaje de heterogamia, es decir, de mayor propensión a casarse fuera del grupo o calidad al que se pertenece.

De acuerdo a lo anterior, la mayor mezcla entre diferentes calidades o heterogamia se da en regiones norteñas, villas de españoles o en pueblos mineros durante el siglo XVIII, como es el caso de Charcas, San Luis Potosí (aunque su mayor información es del siglo XVII), San Luis de la Paz, Guanajuato, León, Guanajuato y Aguascalientes. Las castas en el norte son el grupo de mayor heterogamia, lo que posibilitarían una sociedad más flexible y abierta a los cambios. 
Cuadro 5. Matrimonios mixtos en la Nueva España. Porcentaje de heterogamia. Promedios

\begin{tabular}{|c|c|c|c|c|}
\hline SUR & Indios & Españoles & Castas & Total \\
\hline $\begin{array}{l}\text { Norma A. Castillo Palma, Pueblo de Indios, Cholula, I674- } \\
\text { I69i }\end{array}$ & s.d. & 25 & 49 & 37 \\
\hline $\begin{array}{l}\text { Norma Castillo A. Palma, Pueblo de Indios, Cholula, I692- } \\
\text { I722, I754-I779 }\end{array}$ & s.d. & 29 & 64.6 & 46.8 \\
\hline Patrick J. Carroll, Xalapa, Ver., I645 & $3 \cdot 5$ & 7 & 21.5 & I0.6 \\
\hline Patrick J. Carroll, Xalapa, Ver., I7I5, I750, I805 & $\mathrm{I} 3.5$ & 17.2 & $27 \cdot 7$ & $19 \cdot 4$ \\
\hline $\begin{array}{l}\text { América Molina del Villar, Atlacomulco, Edo. de México, } \\
\text { I696-I860. }\end{array}$ & 6.5 & 48 & $17 \cdot 4$ & $23 \cdot 9$ \\
\hline $\begin{array}{l}\text { José Gustavo González Flores, Pueblo de Indios, Taximaroa, } \\
\text { Mich., I667-1823 }\end{array}$ & 3.I & I 8.5 & $33 \cdot 5$ & $22 . \mathrm{I}$ \\
\hline \multicolumn{5}{|l|}{ SEPTENTRIÓN } \\
\hline $\begin{array}{l}\text { Marcelo Carmagnani, Pueblo minero de frontera, Charcas, } \\
\text { San Luis Potosí, I635-1723 }\end{array}$ & 28.I & 20.8 & 63.4 & 44 \\
\hline Cecilia Rabell, San Luis de la Paz, Gto., I720-I8ıo & I0.7 & $35 \cdot 2$ & $47 \cdot 5$ & $35 \cdot 2$ \\
\hline $\begin{array}{l}\text { David Brading y Celia Wu, Villa de españoles, León, Gto., } \\
\text { I782-I793 }\end{array}$ & 47.8 & 24 & 44.6 & 40.2 \\
\hline VMGE, Villa y pueblos de indios, Aguascalientes, siglo XVII & 16.5 & 8.4 & $4^{2}$ & 27.2 \\
\hline $\begin{array}{l}\text { VMGE, Villa y pueblos de indios, Aguascalientes, siglo } \\
\text { XVIII }\end{array}$ & 20.5 & 19.4 & 62 & $4 \mathrm{I}$ \\
\hline
\end{tabular}

Fuentes: Norma Angélica Castillo Palma, Cholula. Sociedad mestiza en ciudad india, segunda edición (México: Plaza y Valdés, Universidad Autónoma Metropolitana. 2008), desafortunadamente no tiene completa la información de la población india, en contrapartida presenta un alto porcentaje de heterogamia en castas; Patrick J. 
Carroll, Población negra en el Veracruz colonial. Raza, etnicidad y desarrollo regional (Xalapa:

Universidad Veracruzana, 20I4), Tabla A.24, 350-351; José Gustavo González

Flores, Mestizaje de papel, Dinámica demográfica y familias de calidad múltiple en Taximaroa

(1667-1826) (Zamora: El Colegio de Michoacán, Universidad Autónoma de Coahuila,

2016); América Molina del Villar, "Comportamiento y distribución de la población en

Santa María Guadalupe, Atlacomulco, I686-I860”, en Problemas demográficos vistos desde

la historia. Análisis de fuentes, comportamientos y distribución de la población en México, siglos

XVI-XIX, coord. América Molina del Villar y David Navarrete Gómez, (Zamora: El

Colegio de Michoacán, Ciesas), 2006, cuadro 3, I4I, tiene un alto porcentaje de "Sin

registro": $29.4 \%$; David Brading y Celia Wu, "Population Growth and Crisis: León, I720-

1860", Journal of Latin American Studies 5(I) (I973): I-36; Marcelo Carmagnani,

"Demografía y sociedad: La estructura social de los centros mineros del norte de México,

I600-I720", Historia Mexicana XXI(3) (enero-marzo I972): 4I9-459; Cecilia Rabell,

"Matrimonio y raza en una parroquia rural: San Luis de la Paz, Guanajuato, I715-

I8Io", Historia Mexicana XLII(I) (Ig92); Víctor M. González Esparza, Resignificar el

mestizaje en Tierra Adentro, Aguascalientes, ss. XVII-XVIII(Aguascalientes: UAA, en

prensa).

Una hipótesis que he tratado de mostrar, que requiere desde luego de más estudios comparativos, es que la expansión hacia el norte estuvo acompañada de nuevos grupos sociales, particularmente de castas, los cuales posibilitaron una de las mezclas sociales más intensas y variadas de las conocidas hasta ese momento en América. Para el siglo XVIII, si bien las castas fue el grupo con más heterogamia, españoles e indios también participarían de esta tendencia a erosionar la endogamia, no obstante algunas políticas que trataron de frenarla. Eso lo observó Humboldt, después de visitar Colombia y Perú, cuando reflexionó sobre el gran recorrido que realizaron las poblaciones de cuatro continentes para formar el gran crisol de la Nueva España, del cual surgiría la nación mexicana. ${ }^{43}$

\section{Reflexiones finales}

El caso de Aguascalientes que hemos analizado a partir fundamentalmente de los matrimonios mixtos, un indicador sensible para mostrar incluso la flexibilidad del sistema, ofrece algunas conclusiones que pueden compararse para Tierra Adentro, y en general para la Nueva España. Una primera es la importancia de las castas en Tierra Adentro, no sólo en las costas novohispanas, dado su papel como "catalizador" para la interacción social; es decir, las castas en los siglos XVII y XVIII impulsaron la "mescolanza social" al punto de que sin su presencia el mestizaje no puede explicarse. En la ensalada que pensara Sor Juana para sus villancicos, este ingrediente fue fundamental para evitar la existencia de un sistema rígido, tal y como fue pensado por las elites españolas y criollas, de ahí su carácter incluso transgresor.

Otro aspecto importante es que la tendencia endogámica de indígenas y españoles, vista en el largo plazo, se fue erosionando particularmente en el siglo XVIII, de tal manera que la interacción de los diferentes grupos fue cada vez más amplia y heterogámica. Esta tendencia a la heterogamia, en un primer ejercicio comparativo, la observamos sobre todo en los registros 
de villas y pueblos en el septentrión novohispano o la "Norteamérica española" como la llamara John Tutino, lo cual nos habla de diferencias importantes en la dinámica del mestizaje.

En términos amplios, me parece necesario resignificar el mestizaje, otorgarle nuevos contenidos históricos que muestren la diversidad y pluralidad en la conformación de la sociedad mexicana. Ello nos puede prevenir de identidades raciales y, desde el campo de la historia, poder contribuir a desestabilizar viejas certezas producto del nacionalismo criollo o de los esencialismos. Espero que este trabajo se inscriba en esta perspectiva de resignificar el mestizaje.

\section{Agradecimientos}

El artículo forma parte del Proyecto de Investigación del autor autorizado por la Universidad Autónoma de Aguascalientes, sobre El Mestizaje y los Afrodescendientes en Aguascalientes. Agradezco la colaboración de Enrique Jiménez y de Alfonso Quezada en la recopilación y procesamiento de la información, sin su apoyo hubiera sido más largo y tedioso utilizar los registros y las bases de datos. De manera especial, agradezco los comentarios de Juan Pedro Viqueira que me permitieron darle más consistencia al texto, y al Seminario efímero del INAH cuyos integrantes (Anna Pelz, Mario Pérez y Christian Medina, entre otros) vieron los primeros esfuerzos hace ya 5 años. Igualmente el autor agradece a los anónimos dictaminadores de la revista Relaciones Estudios de Historia y Sociedad por sus precisos y sugerentes comentarios.

\section{Archivos}

Archivo General de la Nación, México (AGNM), Fondo: Padrones, 5

Archivos Parroquiales, Aguascalientes, I602-I800. Family Search, Matrimonios, Bautizos y Defunciones, siglos XVII y XVIII.

\section{Bibliografía}

ACUÑA, René. "Relación del Pueblo de Teucaltiche", Relaciones geográficas del siglo XVI: Nueva Galicia. México: Universidad Nacional Autónoma de México, I988, 292-308.

AGUILAR RIVERA, José Antonio. El sonido y la furia. La persuasión multicultural en México y en Estados Unidos. México: Taurus Historia, 2012.

AGUIRRE BELTRÁN, Gonzalo. El proceso de aculturación. México: Universidad Nacional Autónoma de México, I957.

La población negra de México. Estudio etnohistórico. Obra antropológica, II. Tercera edición aumentada y corregida. México: Fondo de Cultura Económica, Instituto Nacional Indigenista, Universidad Veracruzana, Gobierno del Estado de Veracruz, I989. 
. El "negro" esclavo en Nueva España. La formación colonial, la medicina popular y otros ensayos. Obra Antropológica XVI. México: Ciesas, Fondo de Cultura Económica, Instituto Nacional Indigenista, Universidad Veracruzana, I994.

ALBERRO, Solange. "El amancebamiento en los siglos XVI y XVII: el medio eventual de medrar". En Familia y poder en Nueva España. Memorias del Tercer Simposio de Historia de las Mentalidades, México: Instituto Nacional de Antropología e Historia, I991,I55-166.

ARREGUI, Domingo Lázaro de. Descripción de la Nueva Galicia, Estudio preliminar de Francois Chevalier. Presentación de la edición en español de Carmen Castañeda. Guadalajara: Gobierno de Jalisco, I980.

BAKEWELL, P. J. Minería y sociedad en el México colonial, Zacatecas (1546-17oo). Segunda reimpresión. México: Fondo de Cultura Económica, 1997.

BECERRA JIMÉNEZ, Celina G. "Población africana en una sociedad ranchera". Estudios Jaliscienses (49) (agosto 2002).

Gobierno, justicia e instituciones en la Nueva Galicia. La alcaldía mayor de Santa María de los Lagos, 1563-1750. Guadalajara: Universidad de Guadalajara, 2008.

Indios, españoles y africanos en los Altos de Jalisco. Jalostotitlán, 1650-1780. Guadalajara: CULAgos, Universidad de Guadalajara, 2015.

BERNAND, Carmen y Sergio GRUZINSKI. Historia del Nuevo Mundo, Tomo II, Los mestizajes, 1550-1640. México: Fondo de Cultura Económica, I999.

BERTHE, Jean-Pierre. "El Licenciado Gaspar de la Fuente y su visita Tierra Adentro, I608-I609". En Sociedades en construcción. La Nueva Galicia según la visita de oidores (1606-1616), I37. Guadalajara: Universidad de Guadalajara, CEMCA, 2000.

BRADING, David A. Orbe Indiano, De la monarquía católica a la república criolla, 1492-1867. México: Fondo de Cultura Económica, I99I.

. Mineros y comerciantes en el México borbónico, 1763-1810. México: Fondo de Cultura Económica, I993.

"Grupos étnicos, clases y estructura ocupacional en Guanajuato (I792)". En Historia y población en México. Lecturas de Historia Mexicana. México: El Colegio de México, 1994, 240260.

La Nueva España: patria y religión. México: Fondo de Cultura Económica, 2015.

BRADING, David y Celia WU. "Population Growth and Crisis: León, I720-I860". Journal of Latin American Studies 5(I) (1973): 136.

Relaciones Estudios de Historia y Sociedad, vol. XL, núm 157, 2019 
BURKE, Peter. Hibridismo cultural. Madrid: Ediciones Akal, 20 оо.

CALLEJA, Félix. "Descripción de la Subdelegación de Aguascalientes". Archivo General de la Nación, Padrones, vol. 5 , fojas I-IO.

CALVO, Thomas. Demografía de una parroquia mexicana. Colección Científica. México: Instituto Nacional de Antropología e Historia, I973.

. "Concubinato y Mestizaje en el medio urbano: el caso de Guadalajara en el siglo XVII". Revista de Indias XLIV(I73) (1984): 203-2I2.

La Nueva Galicia en los siglos XVI y XVII. Guadalajara: El Colegio de Jalisco, CEMCA, 1989.

Poder, religión y sociedad en la Guadalajara del siglo XVII. México: CEMCA, I99I.

- "Demografía y economía: La coyuntura en Nueva Galicia en el siglo XVII". Historia Mexicana XLI(4) (1992).

. Guadalajara y su región en el siglo XVII. Población y Economía. México: CEMCA, H. Ayuntamiento de Guadalajara, I992.

CARBAJAL LÓPEZ, David. "Reflexiones metodológicas sobre el mestizaje en la Nueva España. Una propuesta a partir de las familias del real de Bolaños, I740-I822". Letras Históricas (I) (otoño-invierno 2009): 13-38.

La población en Bolaños, 1740-1848. Dinámica demográfica, familia y mestizaje. México: El Colegio de Michoacán, 2008.

, coord. Familias pluriétnicas y mestizaje en la Nueva España y el Río de la Plata. Guadalajara: Universidad de Guadalajara, 2014.

CARMAGNANI, Marcelo. "Demografía y sociedad: La estructura social de los centros mineros del norte de México, I600-I720". Historia Mexicana XXI (3) (enero-marzo I972): 419-459.

CARROL, Patrick James. "Los mexicanos negros, el mestizaje y los fundamentos olvidados de la 'raza cósmica', una perspectiva regional", Historia Mexicana XLIV(3) (I995): 403-438.

"El debate académico sobre los significados sociales entre clase y raza en el México del siglo XVIII". En Debates históricos contemporáneos: africanos y afrodescendientes en México y Centroamérica, dir. María Elisa Velásquez. México: Centro de Estudios Mexicanos y Centroamericanos, 20II. OpenEdition: http://books.openedition.org/cemca/ız2, en la fecha: $28 / 10 / 2016$ 
CASTAÑEDA, Carmen y Laura G. GÓMEZ. "La población de Guadalajara de acuerdo con el padrón militar de i79I y el censo de la intendencia de I793”. Historias (45) (enero-abril 2000): $45-65$.

CASTILlO PALMA, Norma Angélica. "Matrimonios mixtos y cruce de la barrera de color como vías para el mestizaje de la población negra y mulata", Signos Históricos II(4) (diciembre 2000):IO7-I37.

Cholula. Sociedad mestiza en ciudad india. Segunda edición. México: Plaza y Valdés, Universidad Autónoma Metropolitana, 2008.

CHAUNU, Pierre, "Los elementos de larga duración en la sociedad y la civilización del siglo XVII". En Historia cuantitativa, historia serial. México: Fondo de Cultura Económica, I987.

COMMONS, Áurea. "La Población de Nueva España en I790". Tempus (3) (primavera 1995): 7III.

COSAMALÓN AGUILAR, Jesús A. Indios detrás de la muralla. Matrimonios, indígenas y Convivencia interracial en Santa Ana (Lima, 1795-1820). Lima: Pontificia Universidad Católica del Perú, I999.

CRAMAUSSEL, Chantal. "Ritmos de poblamiento y demografía en la Nueva Vizcaya". En Demografía y poblamiento del territorio. La Nueva España y México (siglos XVI-XIX), ed. Chantal Cramaussel, r23-I44. Zamora: El Colegio de Michoacán, 2009.

"Mestizaje y familias pluriétnicas en la villa de San Felipe El Real de Chihuahua y multiplicación de los mulatos en el septentrión novohispano durante el siglo XVIII". En Familias pluriétnicas y mestizaje en la Nueva España y el Río de la Plata, coord. David Carbajal López, I7-45. Guadalajara: Universidad de Guadalajara, 2014.

GARCÍA DÍAZ, Jorge. "Esclavitud, mestizaje y dinámica demográfica en la Villa de la Asunción de las Aguas Calientes, siglo XVII". Letras Históricas (2) (primavera-verano 20I0): 37-55.

GÓMEZ MATA, Carlos. Los negros de Santa María de los Lagos. Presencia, esclavitud y mestizaje. Segunda edición. Lagos de Moreno: Universidad Siglo XXI, Gobierno de Lagos de Moreno, 2016.

GÓMEZ MATA, Mario. "La muerte de Hernando de Cárdenas en el puesto de Aguascalientes en 1572 y sus negocios en Los Lagos, Guanajuato y Zacatecas". En Nuestras Raíces, Órgano Oficial del Archivo Histórico e Lagos de Moreno, Jalisco (85) (enero-febrero 2011).

GÓMEZ SERRANO, Jesús y Francisco Javier DELGADO AGUILAR. Un mayorazgo sin fundación. La familia Rincón Gallardo y su latifundio de Ciénega de Mata, 1593-1740. Aguascalientes: Instituto Cultural de Aguascalientes, UAA, 2006. 
GONZALBO AIZPURU, Pilar, coord. Historia de la familia, México: Universidad Autónoma Metropolitana, Instituto Mora, I993.

_-_-_._Familia y orden colonial. México: El Colegio de México, I998.

Familias iberoamericanas. Historia, identidad y conflictos. México: El Colegio de México, 2OOI.

"Afectos e intereses en los matrimonios de la ciudad de México a fines de la colonia". Historia Mexicana LVI(4) (2007).

. Educación, familia y vida cotidiana en el México virreinal. México: El Colegio de México, 2013 .

"La Trampa de las castas". En La Sociedad Novohispana. ¿Estereotipos y realidades? Solange Alberro y Pilar Gonzalbo, I5-193. México: El Colegio de México, 2013,

GONZALBO AIZPURU, Pilar y Cecilia RABELL, comp. La familia en el mundo iberoamericano. México: Universidad Nacional Autónoma de México, 1994.

GONZÁLEZ ESPARZA, Víctor M. Resignificar el mestizaje en Tierra Adentro, Aguascalientes, ss. XVII-XVIII. Aguascalientes: UAA, en prensa.

GONZÁLEZ FLORES, José Gustavo. Mestizaje de papel. Dinámicas demográficas y familias de calidad múltiple en Taximaroa (1667-1826). Zamora: El Colegio de Michoacán, Universidad Autónoma de Coahuila, 2016.

GRUZINSKI, Serge. El pensamiento mestizo. Barcelona: Ediciones Paidós Ibérica, 2000.

GUTIÉRREZ GUTIÉRREZ, José Antonio. "Introducción”. Padrón Parroquial de Aguascalientes, 1770, Aguascalientes: Archivo Histórico de Aguascalientes, I990.

Aguascalientes y su región de influencia hasta 1810. Sociedad y Política. Guadalajara: Universidad de Guadalajara, 1998.

, comp. Colección de documentos para la historia de la Diócesis de Aguascalientes. Vol. I, siglos XVI y XVII. Aguascalientes: Universidad Autónoma de Aguascalientes, Obispado de Aguascalientes, I999, I42-I43.

. "Aguascalientes a través del Padrón de i648". Folio, año I(I) (I999).

HOFFMANN, Odile. "Negros y afromestizos en México: viejas y nuevas lecturas de un mundo olvidado". Revista Mexicana de Sociología68(I) (enero-marzo 2006): I03-I35.

Relaciones Estudios de Historia y Sociedad, vol. XL, núm 157, 2019

166 
HUMBOLDT, Alejandro de. Ensayo político sobre el Reino de la Nueva España. Colección Sepan Cuantos núm. 39. Sexta edición. Estudio preliminar, revisión del texto, cotejos, notas y anexos de Juan A. Ortega Mediana. México: Editorial Porrúa, 2002.

JUÁREZ LUÉVANO, Luis Benedicto. Los esclavos, los africanos y afrodescendientes, en la villa de Nuestra señora de la Asunción de las Aguas Calientes (1650-1750). Tesis de Licenciatura en Historia, Universidad Nacional Autónoma de México, 2013.

KONETZKE, Richard. "El mestizaje y su importancia en el desarrollo de la población hispanoamericana durante la época colonial". Revista de Indias, año VII(23-24) (enero-marzo, abril-junio I946).

KLEIN, Herbert S. y Ben VINSON III. La esclavitud en América latina y el Caribe. México: El Colegio de México, 2013.

LACUEVA MUÑOZ, Jaime. La plata del rey y sus vasallos. Minería y metalurgia en México (siglos XVI y XVII). Sevilla: Consejo Superior de investigaciones Científicas, Escuela de Estudios Hispano-Americanos, Universidad de Sevilla, zoıо.

MALVIDO, Elsa. La población, siglos XVI-XIX. En Historia económica de México, coord. Enrique Semo. México: Universidad Nacional Autónoma de México, OCEANO, 2006.

MCCAA, Robert. "Gustos de los padres, inclinaciones de los novios y reglas de una feria nupcial: Parral, I770-I8I4", Historia Mexicana 40(4) (I991): 579-6I3.

"Marriageways in Mexico and Spain, I500-1900". Continuity and Change 9(I) (mayo I994): II-43.

MCCAA, Robert et al. "Race and Class in Colonial Latin America: A Critique", Comparative Studies in Society and History 2I(3) (julio I979): 42I-433.

MEDINA, Consuelo. Aguascalientes en el siglo XVII. Economía y sociedad, el caso de la esclavitud. Tesis de Licenciatura en Historia, Universidad Autónoma de Aguascalientes, 1995.

MENÉNDEZ VALDÉS, José. Descripción y Censo General de la Intendencia de Guadalajara, 17891793. Estudio preliminar de Ramón Ma. Serrera. Guadalajara: Gobierno del Estado de Jalisco, I980.

MINTZ, Sidney W. y Richard PRICE. El origen de la cultura africano-americana. Una perspectiva antropológica. México: Ciesas, Universidad Autónoma Metropolitana, Universidad Iberoamericana, 2012.

MOLINA DEL VILLAR, América y David NAVARRETE GÓMEZ, coord. Problemas demográficos vistos desde la historia. Análisis de fuentes, comportamiento y distribución de la población en México, siglos XVI-XIX. México: El Colegio de Michoacán, Ciesas, 2006.

Relaciones Estudios de Historia y Sociedad, vol. XL, núm I57, 2019

167 
MORIN, Claude. Santa Inés Zacatelco (1646-1812), Contribución a la demografía histórica del México colonial. Colección Científica. México: Instituto Nacional de Antropología e Historia, I973.

MÖRNER, Magnus. El mestizaje en la Historia de Ibero-América. Estocolmo: Biblioteca e Instituto de Estudios Ibero-Americanos de la escuela de Ciencias Económicas, I960, 46.

La mezcla de razas en la Historia de América Latina. Barcelona: Editorial Paidós, I969.

Estado, razas y cambio social en la Hispanoamérica colonial. México: SEP/Setentas I28, I973.

MOTA Y ESCOBAR, Alonso de la. Descripción Geográfica de los Reynos de Nueva Galicia, Nueva Vizcaya y Nuevo León. Guadalajara: Instituto Jalisciense de Antropología e Historia, ig66.

RABELL, Cecilia. "Matrimonio y raza en una parroquia rural: San Luis de la Paz, Guanajuato, I7I5-I8Io". Historia Mexicana 42(I) (julio-septiembre I992): 3-44.

ROJAS, Beatriz. Las instituciones de gobierno y la élite local. Aguascalientes del siglo XVII hasta la Independencia. Zamora: El Colegio de Michoacán, Instituto Mora, I998.

ROJAS VIDALES, Daniela y J. Patricia PÉREZ MUNGUÍA. "El mestizaje, proceso de integración, trascendencia y medidas de control en la Nueva España”. En Negros y morenos en Iberoamérica, adaptación y conflicto. Juan Manuel de la Serna, i9-46. México: Centro de Investigaciones sobre América Latina y el Caribe, Universidad Nacional Autónoma de México, 2015.

ROMANO, Ruggiero. Coyunturas opuestas. La crisis del siglo XVII en Europa e Hispanoamérica. México: Fideicomiso Historia de las Américas, El Colegio de México, Fondo de Cultura Económica, 1993 .

Mecanismos y elementos del sistema económico colonial americano, siglos XVI-XVIII. México: Fideicomiso Historia de las Américas, El Colegio de México, Fondo de Cultura Económica, 2004.

SÁNCHEZ-ALBORNOZ, Nicolás. La población de América latina, desde los tiempos precolombinios al año 200o. Segunda edición. Madrid: Alianza editorial, I977.

La población de América Latina. México: El Colegio de México, 2016.

SEED, Patricia. Amar, honrar y obedecer en el México colonial. Conflictos en torno a la elección matrimonial, 1574-1821. México: Alianza editorial, Conaculta, I991.

SEED, Patricia y Philip F. RUST. "Estate and Class in Colonial Oaxaca revisited", Comparative Studies in Society and History 25(4) (octubre 1983): 707-710. 
SEMPAT ASSADOURIAN, Carlos. Zacatecas. Conquista y transformación de la frontera en el siglo XVI. Minas de plata, guerra y evangelización. México: El Colegio de México, 2008.

SERNA, Juan Manuel de la. "Esclavizados y libres: Historia e Historiografía de México". En Cartografías afrolatinoamericanas: perspectivas situadas para análisis transfronterizos. Buenos Aires: Ed. Biblos, 2013, 263-273.

STRAUSS, David J. "Measuring endogamy", Social Science Research 6(3) (1977): 225-245.

TAYLOR, William B. y John K. CHANCE. "Estate and Class in a Colonial City: Oaxaca in I792". Comparative Studies in Society and History.9(4) (octubre I977): 454-487.

TORRES FRANCO, Carmen Paulina. ¿Entre parientes? Demografía, familias y estrategias matrimoniales en la parroquia de Nuestra Señora de la Encarnación, 1778-1822. Tesis de Doctorado, El Colegio de Michoacán, 2013.

TUTINO, John. Creando un nuevo mundo. Los orígenes del capitalismo en el Bajío y la Norteamérica española. México: Fondo de Cultura Económica, El Colegio de Michoacán, Universidad Intercultural del Estado de Hidalgo, 2016.

TWINAM, Ann. Purchasing Whiteness. Pardos, Mulattos, and the Quest for Social Mobility in the Spanish Indies. Palo Alto: Stanford University Press, 2015.

VELÁZQUEZ, María Elisa. Mujeres de origen africano en la capital novohispana, siglos XVII y XVIII. México: Instituto Nacional de Antropología e Historia, Universidad Nacional Autónoma de México, 2006.

. "Aportes y debates recientes sobre africanos y afrodescendientes en México". En A Contra Corriente. Una Revista de Historia Social y Literatura de América Latina 7(3) (primavera 2010): $419-426$.

"Africanos y afrodescendientes en México: premisas que obstaculizan entender su pasado y presente". Cucuilco I8(5I) (mayo-agosto 20II): II-22.

VELÁZQUEZ, María Elisa y Gabriela ITURRALDE NIETO. Afrodescendientes en México, Una historia de silencio y discriminación. México: CONAPRED, Instituto Nacional de Antropología e Historia, 2012.

VIQUEIRA, Juan Pedro. "Reflexiones contra la noción histórica de mestizaje". Nexos (mayo 2010): $76-83$.

VINSON III, Ben y Bobby VAUGHN. Afroméxico. Herramientas para la historia. México: CIDE, Fondo de Cultura Económica, 2004. 
VINSON III, Ben. Before Mestizaje. The Frontiers of race and Caste in Colonial Mexico. Cambridge: Cambridge University Press, 2018.

WADE, Peter. "Repensando el mestizaje". Revista Colombiana de Antropología (39) (enerodiciembre 2003): 273-196.

ZERMEÑO-PADILLA, Guillermo. "Del Mestizo al mestizaje: Arqueología de un concepto". Memoria y Sociedad I2(24) (enero-junio 2008): 79-95.

Notas

I José Antonio Aguilar Rivera, El sonido y la furia. La persuasión multicultural en México y en Estados Unidos (México: Taurus Historia, 20I2), II2. Para una crítica del uso del concepto de raza y de mestizaje puede verse el ensayo de Juan Pedro Viqueira "Reflexiones contra la noción histórica de mestizaje", Nexos (2010): 76-83. También puede verse con provecho el programa llevado a cabo con motivo de las celebraciones del Centenario "Discutamos México 2oro", dedicado al mestizaje: "Mestizaje y diversidad", coordinado por Enrique Florescano, con la participación de Mauricio Tenorio, José Antonio Aguilar Rivera y Juan Pedro Viqueira; puede verse en: https://youtu.be/aZ8JFszmj2k?list=PLTCv8PKgAsfEEmH_2lNhmZ_BpjJY1605q

Un texto previo que reflexiona sobre el racismo involucrado en el mestizaje es Federico Navarrete, "Mestizos e indios en el México contemporáneo", en Las relaciones interétnicas en México (México: Universidad Nacional Autónoma de México, 2004), 7-20; el autor planteó la necesidad de un nuevo mapa más allá de mestizos e indios.

2 Utilizo los conceptos de época para evitar en lo posible confusiones. El término de "calidades" ayuda a evitar el de razas y lo refiero a todos los grupos que convivieron en la época colonial, el de castas lo refiero a los grupos integrados más allá de españoles e indios, es decir, incluyo a mestizos, castizos, negros (libres o esclavos), mulatos (libres o esclavos), moriscos, lobos y coyotes, que son los grupos que aparecen en los registros parroquiales de Aguascalientes en los siglos XVII y XVIII. Más adelante amplío sobre el porqué de estas preferencias conceptuales.

3 Guillermo Zermeño-Padilla, "Del Mestizo al mestizaje: Arqueología de un concepto", Memoria y Sociedad_I2(24) (enero-junio 2008): 79-95; el autor considera que la transformación del término mestizo al de mestizaje es una creación de Francisco Pimentel y Justo Sierra en el siglo XIX, pero sobre todo de Vasconcelos y, en retrospectiva, va analizando las capas superpuestas; sin embargo, no llega hasta la época novohispana, lo cual deja de lado la excavación más profunda, particularmente para el caso, por ejemplo, de Juan José Eguiara y Eguren, quien fuera de los primeros en plantear que la esencia de los mexicano estaba sólo en la unión entre españoles e indígenas. El reciente estudio de Ben Vinson III, Before Mestizaje. The Frontiers of Race and Caste in Colonial Mexico (Cambridge: Cambridge University Press, 2018), particularmente "Cap. 9 Colonial Bequests" ofrece una guía sobre el surgimiento del concepto del mestizaje como sustitución del "sistema de castas", concepto utilizado por Francisco Bulnes, y de las castas en general, de ahí que su estudio esté dedicado precisamente a las castas ("Before mestizaje") en el periodo colonial. 
4 Gonzalo Aguirre Beltrán, Obra antropológica II, La Población negra de México. Estudio etnohistórico, tercera edición corregida y aumentada (México: Fondo de Cultura Económica, Instituto Nacional Indigenista, Universidad Veracruzana, Gobierno de Veracruz, I998). La invitación a este tipo de historias viene también por el lado de la antropología estadounidense: Sidney W. Mintz y Richard Price, El origen de la cultura africano-americana. Una perspectiva antropológica (México: Ciesas, Universidad Autónoma Metropolitana, Universidad Iberoamericana, 20I2). Para el caso mexicano la bibliografía es cada vez más abundante, una síntesis puede consultarse en el libro de Ben Vinson III y Bobby Vaughn, Afroméxico. Herramientas para la historia (México: CIDE, Fondo de Cultura Económica, 2004), si bien este tipo de introducciones al tema por historiadores estadounidenses han sido criticadas, con razón, por los escasos trabajos citados de estudiosos mexicanos, véase María Elisa Velázquez, "Aportes y debates recientes sobre africanos y afrodescendientes en México", en A Contra Corriente. Una Revista de Historia Social y Literatura de América Latina 7(3) (primavera 20I0): 419-426. Quizá un trabajo complementario en este sentido es el de la misma María Elisa Velázquez y Gabriela Iturralde Nieto, Afrodescendientes en México, Una historia de silencio y discriminación (México: CONAPRED, Instituto Nacional de Antropología e Historia, 20I2). Un libro clave para el estudio de las mujeres afrodescendientes y sus representaciones: María Elisa Velázquez, Mujeres de origen africano en la capital novohispana, siglos XVII y XVIII (México: Instituto Nacional de Antropología e Historia, Universidad Nacional Autónoma de México, 2006). Para una historiografía reciente Juan Manuel de la Serna, "Esclavizados y libres: Historia e Historiografía de México", en Cartografías afrolatinoamericanas: perspectivas situadas para análisis transfronterizos (Buenos Aires: Ed. Biblos, 2013), 263-273.

5 Un texto ya clásico sobre la flexibilidad del llamado "sistema de castas", véase Pilar Gonzalbo, "La Trampa de las castas", en La sociedad novohispana. ¿Estereotipos y realidades?, Solange Alberro y Pilar Gonzalbo, I5-I93 (México: El Colegio de México, 2013). Igualmente provechoso al respecto: Ann Twinam, Purchasing Whiteness: Pardos, Mulatos, and the Quest of Social Mobility in the Spanish Indies (Palo Alto: Stanford University Press, 2015). Es un excelente ejemplo de los procesos de inclusión y exclusión del sistema. Ben Vinson III, Before Mestizaje. Este último es un excelente ejemplo de la contribución de las "castas" a la flexibilidad y elasticidad del sistema.

6 Existen otros indicadores relacionados, como son la edad al matrimonio y la ilegitimidad. Una primera síntesis sobre el primero en términos comparativos, véase Robert $\mathrm{McCaa}$, "Marriageways in Mexico and Spain, I500-Ig00", Continuity and Change g(I) (mayo I994): II-43.

7 Para la agenda política que de ahí se ha derivado: Odile Hoffmann, "Negros y afromestizos en México: viejas y nuevas lecturas de un mundo olvidado", Revista Mexicana de Sociología 68(I) (enero-marzo 2006): I03-I35. María Elisa Velázquez, "Africanos y afrodescendientes en México: premisas que obstaculizan entender su pasado y presente", Cucuilco_I8(5I) (mayo-agosto 20II): II22. Para el caso mexicano quien más desarrolló la recuperación del mestizaje fue Serge Gruzinski, El pensamiento mestizo, Barcelona: Ediciones Paidós Ibérica, 2000). Dos trabajos son claves al respecto: Peter Burke, Hibridismo cultural (Madrid: Ediciones Akal, 2oio) y Peter Wade, "Repensando el mestizaje", Revista Colombiana de Antropología, vol. 39 (enero-diciembre 2003): $273-296$.

Relaciones Estudios de Historia y Sociedad, vol. XL, núm 157, 2019 
8 Richard Konetzke, "El mestizaje y su importancia en el desarrollo de la población durante la época colonial", Revista de Indias (7) (1946): 7-44, 215-237.

9 Magnus Mörner, El mestizaje en la historia de Ibero-América (Estocolmo: Biblioteca e Instituto de Estudios Ibero-Americanos de la Escuela de Ciencias Económicas, Ig60), 46. Posteriormente este trabajo sería ampliado en Magnus Mörner, La mezcla de razas en la historia de América Latina (Barcelona: Editorial Paidós, I,69), y Magnus Mörner, Estado, razas y cambio social en la Hispanoamérica colonial(México: SEP/Setentas I28, 1973).

Io Marcelo Carmagnani, "Demografía y Sociedad: La estructura social de los centros mineros del norte de México, I600-I720", Historia Mexicana XXI(3) (enero-marzo I972): 419-459.

II Cecilia Rabell, "Matrimonio y raza en una parroquia rural: San Luis de la Paz, Guanajuato, I7I5-I8I0", Historia Mexicana XLII(I) (I992): 5, cuadro I, I9. Llama la atención el grado en que los españoles también se mezclaban en esta región. Pilar Gonzalbo también estudió el caso de matrimonios mixtos en: "Afectos e intereses en los matrimonios de la ciudad de México a fines de la colonia”, Historia MexicanaLVI(4) (2007). No obstante la escasa información para el caso de los indígenas, la autora muestra para diez años de la segunda mitad del siglo XVIII la alta endogamia entre españoles (80 \%), y la mayor exogamia entre mestizos (50\% se casaban con la misma calidad) y otras castas (sólo un $22 \%$ se casaba entre sí). Hay que reconocer la mayor incidencia de historiadoras para el estudio de familia y matrimonio en Nueva España, de la cual existe una bibliografía abundante: Pilar Gonzalbo Aizpuru, Familia y orden colonial (México: El Colegio de México, 1998).

I2 Cecilia Rabell, "Matrimonio y raza", 4I.

I3 Patrick James Carrol, "Los mexicanos negros, el mestizaje y los fundamentos olvidados de la 'raza cósmica', una perspectiva regional”, Historia Mexicana XLIV(3) (I995): 403-438.

I4 Carrol, "Los mexicanos negros", 403-404.

I5 Norma Angélica Castillo Palma, "Matrimonios mixtos y cruce de la barrera de color como vías para el mestizaje de la población negra y mulata", Signos Históricos II(4) (diciembre 200o): I07-I37. Norma Angélica Castillo Palma, Cholula. Sociedad mestiza en ciudad india, segunda edición (México: Plaza y Valdés, Universidad Autónoma Metropolitana, 2008).

I6 Carrol, "Los mexicanos negros", 432-433. El autor conocía el trabajo de Rabell y de ahí la metáfora de población "puente", los mestizos en el caso de Rabell, los afrodescendientes y los mestizos en el caso de Carrol.

I7 Castillo Palma, "Matrimonios mixtos" y Castillo Palma, Cholula. Sociedad mestiza.

I8 David Carbajal, La población en Bolaños, 1740-1848. Dinámica demográfica, familia y mestizaje (Zamora: El Colegio de Michoacán, 2008), I2I, el autor menciona un porcentaje de exogamia cercano al 40 \% en general, en comparación al $25 \%$ que había señalado McCaa para el 
caso de Parral; Chantal Cramaussel, "Mestizaje y familias pluriétnicas en la villa de San Felipe El Real de Chihuahua y multiplicación de los mulatos en el septentrión novohispano durante el siglo XVIII", en Familias pluriétnicas y Mestizaje en la Nueva España y el Río de la Plata, coord. David Carbajal López, I7-45 (Guadalajara: Universidad de Guadalajara, 20I4). José Gustavo González Flores, Mestizaje de papel. Dinámicas demográficas y familias de calidad múltiple en Taximaroa (16671826) (Zamora: El Colegio de Michoacán. Universidad Autónoma de Coahuila, 20i6). Carmen Paulina Torres Franco, ¿Entre parientes? Demografía, familias y estrategias matrimoniales en la parroquia de Nuestra Señora de la Encarnación, 1778-1822 (Tesis de doctorado, El Colegio de Michoacán, 2013), Iz2-I33, menciona un porcentaje de $28 \%$ de exogamia, y en general su idea es enfatizar los matrimonios endogámicos en una parroquia cercana a Aguascalientes, por cierto con mayor porcentaje de población española.

I9 William B. Taylor y John K. Chance, "Estate and Class in a Colonial City: Oaxaca in I792", Comparative Studies in Society and History I9(4) (octubre I977): 454-487.

2o William B. Taylor, "Estate and Class", 485.

2I Robert McCaa, Stuart B. Schwartz y Arturo Grubessich, "Race and Class in Colonial Latin America: A Critique", Comparative Studies in Society and History 2I(3) (julio I979): 42I-433.

22 Robert McCaa, "Race and Class", 423. El autor mantuvo la idea de una alta endogamia en las "ferias nupciales" por ejemplo de Parral, Chihuahua: Robert McCaa, "Gustos de los padres, inclinaciones de los novios y reglas de una feria nupcial colonial: Parral, I770-I8I4", Historia Mexicana XL(4) (I99I): 579-6I3.

23 Patricia Seed y Philip F. Rust, "Estate and Class in Colonial Oaxaca revisited", Comparative Studies in Society and History 25(4) (octubre 1983): 707-710.

24 Mario Gómez Mata, "La muerte de Hernando de Cárdenas en el puesto de Aguascalientes en 1572 y sus negocios en Los Lagos, Guanajuato y Zacatecas", Nuestras Raíces 2 Órgano Oficial del Archivo Histórico e Lagos de Moreno, Jalisco (85) (septiembre-octubre 20II): 36.

25 René Acuña, "Relación del Pueblo de Teucaltiche", Relaciones Geográficas del siglo XVI: Nueva Galicia (México: Universidad Nacional Autónoma de México, r988), 292-308.

26 Alonso de la Mota y Escobar, Descripción Geográfica de los Reynos de Nueva Galicia, Nueva Vizcaya y Nuevo León (Guadalajara: Instituto Jalisciense de Antropología e Historia, 1966), 5758.

27 Domingo Lázaro de Arregui, Descripción de la Nueva Galicia, Estudio preliminar de Francois Chevalier, Presentación de la edición en español de Carmen Castañeda (Guadalajara: Gobierno de Jalisco, I980), i6o. Subrayado de VMGE. 
28 Carlos Sempat Assadourian, Zacatecas. Conquista y transformación de la frontera en el siglo XVI. Minas de plata, guerra y evangelización_(México: El Colegio de México, 20o8). Para un mayor conocimiento de los cambios de esta política.

29 Lean-Pierre Berthe, "El Licenciado Gaspar de la Fuente y su visita Tierra Adentro, I608-I609", en Sociedades en construcción. La Nueva Galicia según la visita de oidores (1606-1616), 5-I54 (Guadalajara: Universidad de Guadalajara, CEMCA, 2000). El texto del oidor tiene referencias hasta I6Io.

30 Thomas Calvo, Demografía de una parroquia mexicana, Colección Científica (México: Instituto Nacional de Antropología e Historia, I973); Claude Morin, Santa Inés Zacatelco (1646-1812), Contribución a la demografía histórica del México colonial, Colección Científica (México: Instituto Nacional de Antropología e Historia, I973). Elsa Malvido, La población, siglos XVI-XIX (México: Universidad Nacional Autónoma de México, OCEANO, 2006), quien realizó uno de los primeros ensayos integradores de los avances en este campo. Estos autores reconocían la problemática de los registros y la singularidad de los casos, por lo que se prevenían de generalizaciones dado el escaso número de estudios similares. Quizá ya es tiempo de realizar algunas comparaciones que permitan realizar algunas generalizaciones. Habría que recordar al menos el impulso original de estos autores por realizar una historia más allá de las elites.

3I Marcelo Carmagnani, "Demografía y sociedad: La estructura social de los centros mineros del norte de México, I600-I720", Historia Mexicana XXI(3) (enero-marzo I972): 419-459.

32 Chantal Cramaussel, "Ritmos de poblamiento y demografía en la Nueva Vizcaya", en Demografía y poblamiento del territorio. La Nueva España y México (siglos XVI-XIX), ed. Chantal Cramaussel, I23-I44 (Zamora: El Colegio de Michoacán, 2009). La autora concluye que son "coyunturas opuestas" el poblamiento y la demografía en el septentrión novohispano, en el sentido de que en los momentos más críticos para la población indígena se desarrolla la expansión colonial norteña.

33 Ruggiero Romano, Coyunturas opuestas. La crisis del siglo XVII en Europa e Hispanoamérica (México: Fideicomiso Historia de las Américas, El Colegio de México, Fondo de Cultura Económica, I993). El autor reseña el trabajo de Morineau sobre las "incroyables" gacetas holandesas que registraban el comercio con América, las cuales mostraron efectivamente una época de gran crecimiento a partir de los años sesenta del siglo XVII, páginas 94-96. Jaime Lacueva Muñoz, La plata del rey y sus vasallos. Minería y metalurgia en México (siglos XVI y XVII) (Sevilla: Consejo Superior de Investigaciones Científicas, Escuela de Estudios HispanoAmericanos, Universidad de Sevilla, 20Io), en particular la tabla XIX y cuadro 9, páginas 345347. Este trabajo es más preciso con respecto la misma producción de metales, sobre todo para la Nueva Galicia. A partir de los años sesenta del siglo XVII, la caja real de Guadalajara (incluye Durango y Sombrerete en este momento) por producción total de metales muestra un crecimiento del $40 \%$ en promedio hasta fines del siglo, duplicando prácticamente la recaudación del mismo concepto de la caja de Zacatecas.

Relaciones Estudios de Historia y Sociedad, vol. XL, núm 157, 2019 
34 José Antonio Gutiérrez, "Introducción", Aguascalientes a través del Padrón de 1648, Folio I (Aguascalientes: Archivo Histórico de Aguascalientes, 1999). Sobre los estudios de negros esclavos en Aguascalientes véase Consuelo Medina de la Torre, Aguascalientes en el siglo XVII. Economía y sociedad, el caso de la esclavitud(Tesis de licenciatura en Historia, Universidad Autónoma de Aguascalientes, I995), gr. Jorge García Díaz, "Esclavitud, mestizaje y dinámica demográfica en la Villa de la Asunción de las Aguas Calientes, siglo XVII”, Letras Históricas (2) (primavera-verano 2010): 37-55; quien aprovecha básicamente los datos de Consuelo Medina. Luis Benedicto Juárez Luévano, Los esclavos, los africanos y afrodescendientes, en la villa de Nuestra señora de la Asunción de las Aguas Calientes (1650-1750)(Tesis de licenciatura en Historia, Universidad Nacional Autónoma de México, 2013), I83, aunque promete estudiar afrodescendientes, se concentra en la esclavitud, aunque unos de sus hallazgos fue que pocos eran los esclavos que llegaron de África. El primer trabajo sobre demografía en la villa fue realizado por Helio de Jesús Velasco, gracias al impulso de Carlos Ortega de León. Ambos eran conscientes de que faltaba una mejor recopilación de la información, de ahí que no hubieran publicado esos primeros resultados; para el uso de estos registros sin profundizar en el mestizaje: véase Beatriz Rojas, Las instituciones de gobierno y la élite local. Aguascalientes del siglo XVII hasta la Independencia (Zamora: El Colegio de Michoacán, Instituto Mora, I9g8). Los trabajos pioneros sobre demografía histórica en la Nueva Galicia se deben a Thomas Calvo, La Nueva Galicia en los siglos XVI y XVII (México: CEMCA, El Colegio de Jalisco, Ig89), en particular la Parte I sobre "Demografía y Sociedad"; si bien no se enfoca a las castas deja en claro la presencia de este grupo. Pueden consultarse con provecho los trabajos de Carlos Gómez Mata, Los negros de Santa María de los Lagos, Presencia, esclavitud y mestizaje, segunda edición (Guadalajara: Universidad Siglo XXI, Gobierno de Lagos de Moreno, 2016); igualmente los trabajos de Celina Becerra Jiménez, "Población africana en una sociedad ranchera", Estudios Jaliscienses (49) (agosto 2002); y el reciente libro de la misma autora Celina G. Becerra Jiménez, Indios, españoles y africanos en los Altos de Jalisco, Jalostotitlán, 1650-1780 (Guadalajara: CULagos, Universidad de Guadalajara, 2015).

35 Este tema merece un estudio en especial en relación con la tierra y los tributos. Una hipótesis es que, frente a la presión fiscal, se registraron más tributarios. Para el caso de las castas, también pudo ser una estrategia para pagar menos tributos y, especialmente, para tener derecho a la tierra. Otro tema sin duda es la explicación de las crisis de mortalidad.

36 José Menéndez Valdés, Descripción y Censo General de la Intendencia de Guadalajara, 1789-1793. Estudio Preliminar de Ramón Ma. Serrera, (Guadalajara: Gobierno del Estado de Jalisco, rg8o), III y I53. Carmen Castañeda y Laura G. Gómez, "La población de Guadalajara de acuerdo con el padrón militar de i7gi y el censo de la intendencia de i793" Historias (45) (enero-abril del 2000): 45-65, especialmente el cuadro 7 de la página 60. Áurea Commons, "La Población de Nueva España en 1790", en TEMPUS, Revista de Historia de la FFyL(3) (primavera de 1995): 70-74, especialmente los Cuadros de la Provincia de Guadalajara.

37 Magnus Mörner, El mestizaje en la Historia, 46.

38 Pierre Chaunu, "Los elementos de larga duración en la sociedad y la civilización del siglo XVII", Historia cuantitativa, historia serial(México: Fondo de Cultura Económica, I987), I22. 
39 David Carbajal, La población en Bolaños; Chantal Cramaussel, "Mestizaje y familias pluriétnicas"; José Gustavo González Flores, Mestizaje de papel.

40 Ann Twinam, Purchasing Whiteness. Pardos, Mulattos, and the Quest for Social Mobility in the Spanish Indies (Palo Alto: Stanford University Press, 2015). Los casos que estudia la autora de compra de "blancura" nos muestran una sociedad con alto grado de flexibilidad en donde la Corona, por diversas razones, enfrentaba a las elites criollas al aceptar este cambio de calidades por medio del recurso de "gracias al sacar".

4I Debo a Juan Pedro Viqueira no sólo la referencia de la fórmula para la medición y la necesaria ponderación de los datos, sino también la corrección de los cuadros dadas las diferencias que pueden existir de criterios sobre todo en la endogamia esperada; para el uso de este indicador en Perú véase Jesús A. Cosamalón Aguilar, Indios detrás de la muralla. Matrimonios, indígenas y convivencia interracial en Santa Ana (Lima, 1795-1820) (Lima: Pontificia Universidad Católica del Perú, I999), I45. La propuesta de la fórmula es de David J. Strauss, "Measuring endogamy", Social Science Research 6(3) (1977): 225-245, y para su aplicación en el caso de México véase Robert McCaa et al."Race and Class in Colonial Latin America: A critique", Comparative Studies in Society and History 2I(3) (julio I979): 42I-433. Véase también: Philip F. Rust, "Equality of endogamy: Statistical approaches", Social Science Research I4(I) (marzo 1985): 57-79. Se trata de un primer corte hasta I80o, será fundamental para los próximos años avanzar en el siglo XIX y observar esta dinámica.

42 La fórmula del Îndice de Endogamia propuesto es la siguiente, donde i es la endogamia absoluta:

$\mathrm{K}=(\mathrm{Po}-\mathrm{Pe}) /\left(\mathrm{P}^{*}-\mathrm{Pe}\right)$

$\mathrm{Po}=$ Suma de matrimonios endogámicos registrados/Total general de matrimonios.

$\mathrm{Pe}=$ Suma de matrimonios endogámicos esperables (Ei)/Total general de matrimonios .

$\mathrm{Ei}=\left(\right.$ Novias/total de matrimonios) ${ }^{*}$ novios.

$\mathrm{P}^{*}=$ Número inferior de la suma de novias o novios para cada grupo/total general de

matrimonios.

43 Alejandro de Humboldt, Ensayo político sobre el Reino de la Nueva España, Colección Sepan Cuantos núm. 39, sexta edición, Estudio preliminar, revisión del texto, cotejos, notas y anexos de Juan A. Ortega Mediana (México: Editorial Porrúa, 2002), 89-go.

\section{Víctor Manuel González Esparza}

Ph. D. Latin American Studies, Tulane University, 1997. Adscripción: Profesor-Investigador de Tiempo Completo, Departamento de Historia-Universidad Autónoma de Aguascalientes. Líneas de investigación: Historia social y cultural, Historia demográfica e Historia del arte. Publicaciones recientes: Resignificar el mestizaje Tierra Adentro. Aguascalientes, Nueva Galicia, siglos XVII y XVIII. Aguascalientes: El Colegio de San Luis, Universidad Autónoma de Aguascalientes, 2018; Trompo a la uña. Breve historia de Aguascalientes. México: Eximia, 2017; Dejando los restos del 
naufragio. Fragmentos para una historia cultural. Aguascalientes: Universidad Autónoma de Aguascalientes, 2016. 